Journal of Engineering and Applied Sciences 14 (Special Issue 5): 9048-9055, 2019

ISSN: 1816-949X

(C) Medwell Journals, 2019

\title{
Enhancement of Heat Dissipation from Computer Processor using Layer Copper-Aluminum Composite Materials
}

\author{
Sameer Hashim Ameen, Deyaa Mohammed Noori Mahmood and Younus Fahad Breesam \\ Institute of Technical Instructors Trainers, Middle Technical University, Baghdad, Iraq \\ Sameer71hashim@yahoo.com
}

\begin{abstract}
Many computers suffer from excessive temperature rise due to continuous use or the use of software that needs high processing speed or use of computers in high temperature-warming environments such as countries in the Middle East. Computer efficiency is directly related to the efficiency of the CPU in data processing and any lag due to high temperatures may result in software damage. Heat sink is a device mounted on the processor that works to dissipate generated heat in the processor to surrounding ambient by conduction first and later by convection. Enhancing heat dissipation is achieved by cutting a piece of aluminum of $(41 \times 38 \times 3 \mathrm{~mm})$ from the base of a typical heat sink and then compensate it by same size of new material (copper). The adding of a copper piece will increase the heat transfer by conduction due to having higher thermal conductivity than aluminum. On other hands, it makes contact to the processor lower surface extra smooth due to a high reduction in the coefficient of friction is achieved which reached to $36.1 \%$ compared to the old heat sink surface that resaecrh to eliminate convection accompanying to non-complete contact between the processor surface and rough surface of the ordinary aluminum heat sink. The copper-aluminum heat sink has a higher factor of safety (for yield stress) reached 4.01 compared to only 2.35 in heat sink without copper. Rejection in heat flux with copper is increasing to $23.3 \%$ in addition to higher heat dissipation to weight ratio of $15.5 \%$ when all these items compared to sink without copper. The all numerical investigations are determined in the present work is done using ANSYS Program V.11.
\end{abstract}

Key words: Heat sink, coefficient of friction, heat flux, composite materials, ANSYS, conductivity

\section{INTRODUCTION}

The heat sink is that part in computer processor work to absorbs the generated heat in processor surface firstly and through extended fins to reject it into surrounding air secondly. The performance of heat dissipation is calculated depends on three principal factors includes shape of the fin, material properties and cooling fan speed (Mohan and Govindarajan, 2011). The air acceleration of $0.026 \mathrm{~m}^{2} / \mathrm{sec}$ is required to dissipated $2-11 \mathrm{~W}$ from CPU that have 18 fins of about $40^{\circ} \mathrm{C}$ peak temperature at fin surface (Carr, 2014).

Pankaj V. employed various shapes of fins in microprocessor such as circular, rectangular, triangular and trapezoidal. Numerical results from ANSYS suggested that the triangular shape of the fin have a better capability of heat dissipation among other shapes of fins because its dissipated more heat flux up to $9 \%$ when its compared with rectangular shape (Baviskar et al., 2016). The increase in the heat sink base from $2.5-5 \mathrm{~mm}$ is produced high dissipation of heat, however, the limitation of size in computer design has restricted this option of modification (Mohan and Govindarajan, 2011). Chiang proposed that increasing the discharge of air flow of the cooling fan of the CPU by adding external fan near the hot processor surface called "sidewall fan" working to enhance the heat dissipation performance (Chiang et al., 2005). The heat rejected from the processor is measured to reach $89.4 \mathrm{~W}$ for assembly of heat sink and fan dimensions of $80 \times 60 \times 50 \mathrm{~mm}$ using fan of $60 \mathrm{~mm}$ diameter in order to reach the difference of temperature between $\mathrm{CPU}$ and ambient air to $35^{\circ} \mathrm{C}$ (Saini and Webb, 2003).

Aluminum alloys are commonly used as material in manufacturing $\mathrm{CPU}$ due to its moderate thermal conductivity, low cost and lightweight. Diamond has higher thermal conductivity (minimum thermal resistance) among all materials of $2000 \mathrm{~W} / \mathrm{msK}$ in compare to only $247 \mathrm{~W} / \mathrm{m}$.K for aluminum or $398 \mathrm{~W} / \mathrm{msK}$ for copper, however, its way expensive material that rarely used (Chung, 2001). Copper has lower thermal resistance than aluminum with slightly higher density (higher weight). Graphite is one of alternative material which has anisotropic high thermal conductivity

Corresponding Author: Sameer Hashim Ameen, Institute of Technical Instructors Trainers,

Middle Technical University, Baghdad, Iraq 
reached to $1500 \mathrm{~W} / \mathrm{msK}$ in one direction but with only $50-60 \mathrm{~W} / \mathrm{msK}$ in other direction (Liu et al., 2012). The disadvantages of graphite are listed as follow:

- Dissipated of heat in from CPU in one axis only and semi isolated in other axes which means totally poor heat rejection to the surrounding

- Low mechanical properties in comparison with aluminum and copper

Graphene is representing a new material of high thermal conductivity $(5300 \mathrm{~W} / \mathrm{msK})$ may be used as alternative material replacing traditional materials (aluminum and copper) in addition of low density and thermal expansion coefficient, respectively (Kumar et al., 2016). The material has low wear resistance against air flow of fan beside very low anisotropic mechanical properties (like graphites).

The heat dissipation from the a processor in personal computer is ranged $(60-130 \mathrm{~W})$ with fan speed $(2850-5000$ $\mathrm{rpm}$ ) in ambient temperature varies from $24-39^{\circ} \mathrm{C}$ in an area limited between $(0.0036-0.0084 \mathrm{~m})$ (Navas et al., 2017). The heat flux developed from the processor in the year 2000 is ranged between $\left(10-15 \mathrm{w} / \mathrm{cm}^{2}\right)$ (Mochizuki et al., 2005).

The present research, a composite copper-aluminum materials to replace aluminum is used as new proposal for manufacturing of heat sink is done using experimental tests for measuring the temperatures and numerical analysis (ANSYS Package) to investigate the thermal performance is achieved. The new combination of the two material is chosen between high thermal conductivity of copper and then higher dissipation of heat from computer is achieved with low cost and light weight.

\section{MATERIALS AND METHODS}

The flowchart in Fig. 1 explains current investigation.

Theory: The processor was dissipated the developed heat (due to the calculations processes) in conduction through adjacent heat sink base, fins and then by force convention from fins surfaces to ambient air. The Fourier's law of conduction in one-dimension through heat sink is as follows (Tewari et al., 2017):

$$
Q=-K A \frac{d T}{d X}
$$

According to the principle of conservation of energy under steady-state condition, Newton's law of assumption isolated closed room with heat input and output as follow (Magadum and Shamrao, 2015):

$$
\mathrm{Q}=\mathrm{mC}_{\mathrm{p}}\left(\mathrm{T}_{\text {air, in }}-\mathrm{T}_{\text {arr out }}\right)
$$

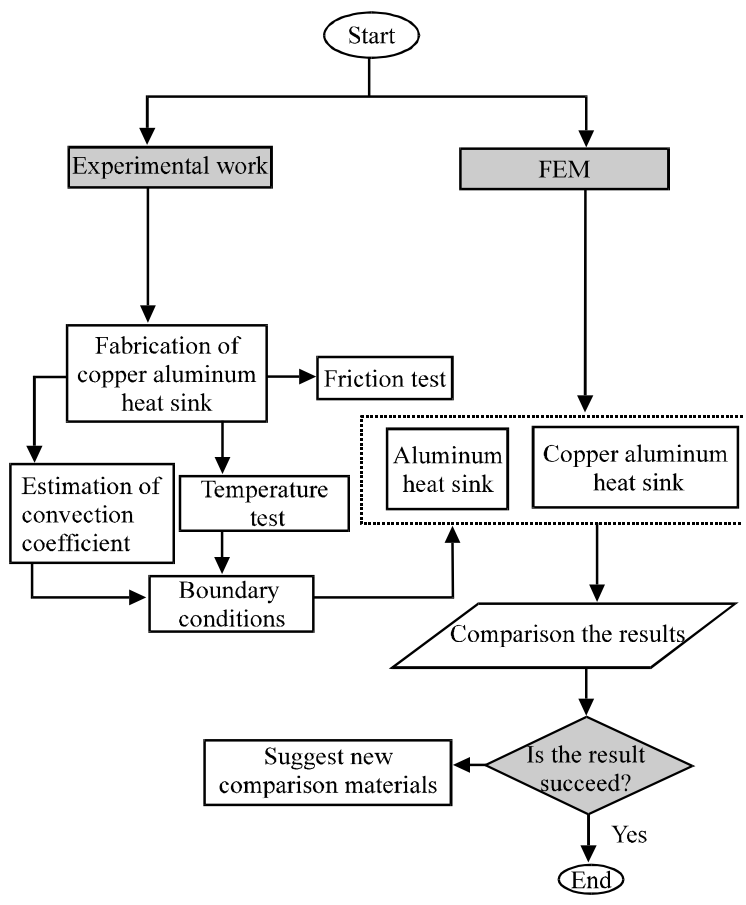

Fig. 1: Methodology of current work

While the convection of heat from fin surface to air is as follow:

$$
\mathrm{Q}=\mathrm{hA}\left(\mathrm{T}_{\mathrm{hs}}-\mathrm{T}_{\mathrm{ar}, \mathrm{av}}\right)
$$

In order to formulate the structural analysis, thermal stresses and deformations, the basic formula of thermal stress is:

$$
\sigma_{\text {th }}=\mathrm{E} \alpha \Delta \mathrm{T}
$$

The developed thermal stress in the interface surface between processor and adjacent base surface of the heat sink is produced temperature difference make expansion in structure developed to increase in pressure directly proportional to increase in the temperature. The pressure introduce is making contraction in structure. Therefore, the total strain in the heat sink is:

$$
\varepsilon_{\mathrm{t}}=\varepsilon_{\mathrm{th}}+\varepsilon_{\mathrm{p}}
$$

Make an assumption of, so, small deformation is determined on interface surface led to putting zero to total strain in Eq. 4 led to:

$$
0=\alpha \Delta \mathrm{T}-\frac{\mathrm{P}}{\mathrm{AE}}
$$

So,

$$
\mathrm{P}=\mathrm{EA} \alpha \Delta \mathrm{T}
$$




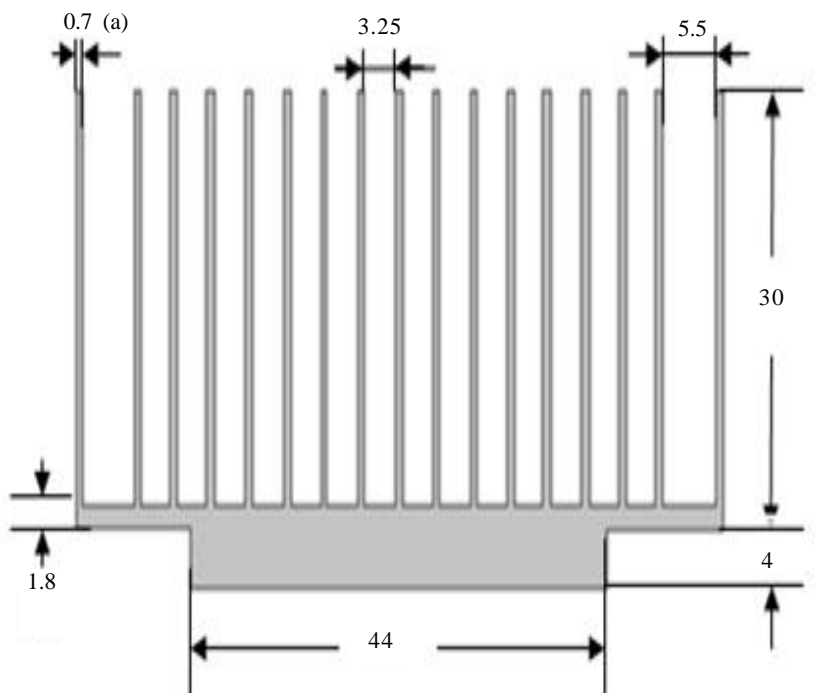

(b)

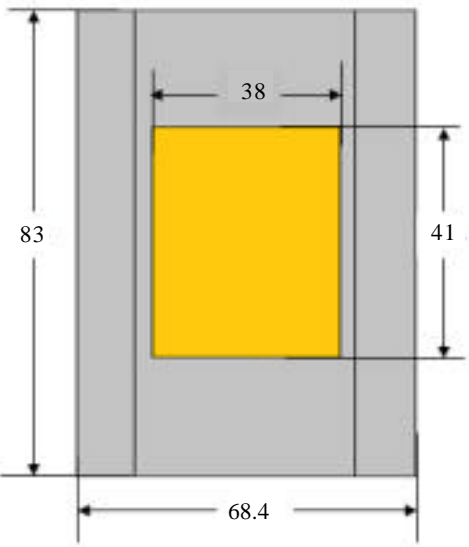

Fig. 2: Heat sink dimensions in mm: a) Front view and b) Bottom view
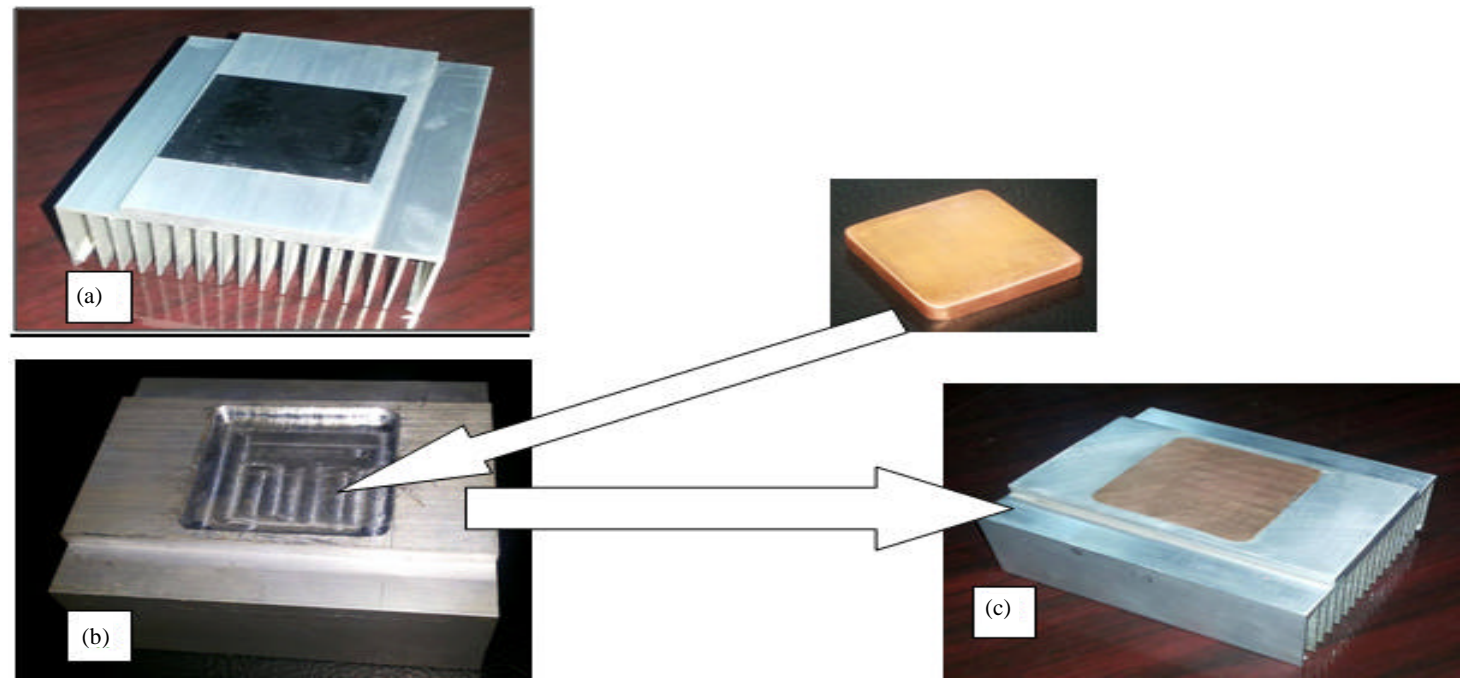

Fig. 3: Fabrication copper-aluminum heat sink: a) Old sink; b) After cutting and c) New sink

Therefore, applied pressures for copper and aluminum are:

$$
\begin{gathered}
P_{c u}=E_{c u} A \alpha_{c u} \Delta T \\
P_{A L}=E_{A L} A \alpha_{A L} \Delta T
\end{gathered}
$$

Fabrication and case study: The heat sink for the desktop processor used in current work has dimensions as shown in Fig. 2 with 17 fins made completely from aluminum. The process of fabrication new heat sink is done firstly by cut piece from base of heat sink in touch with processor $(41 \times 38 \times 3 \mathrm{~mm})$ and then putting a copper piece as conceptions to that cut with usage a thermal grease for insurance complete transmission of heat through developed gaps between two materials as shown in Fig. 3. The mass of a typical heat sink is $166.6 \mathrm{~g}$ while their mass increased up to $10 \%$ when insertion of the copper piece is done. The thermal and structural mechanical properties of two materials under study (aluminum and copper) is listed in Table 1. 
Table 1: Thermal and structural mechanical properties (Chung, 2001)

\begin{tabular}{lcc}
\hline & Materials & \\
\cline { 2 - 3 } Properties & Aluminum & Copper \\
\hline $\mathrm{K}(\mathrm{W} / \mathrm{m} . \mathrm{k})$ & 247 & 398 \\
$\cdot\left(10^{6}\right)$ & 23 & 17 \\
$\cdot\left(\mathrm{g} / \mathrm{cm}^{3}\right)$ & 2.7 & 8.9 \\
$\mathrm{E}\left(\mathrm{GN} / \mathrm{m}^{2}\right)$ & 71 & 110 \\
$\cdot{ }_{\mathrm{y}}\left(\mathrm{MN} / \mathrm{m}^{2}\right)$ & 35 & 69 \\
$\cdot$ & 0.33 & 0.34 \\
\hline
\end{tabular}

\section{RESULTS AND DISCUSSION}

Roughness test: The test of surface roughness for copper (composite sink) and aluminum (old sink) are carried out using ISR-S400 rig (Fig. 4) using contact bar, however, five measuring values are taken for old and composite sinks to insurance of the precised values of friction coefficients. The measuring mean values for the copper and aluminum surfaces, respectively are shown in Fig. 5. The new sink is enhanced contact to the processor (and therefore, more heat dissipation) to about $36.1 \%$ in comparison to aluminum sink. The rough surface makes heat transfer convection and conduction instead of only conduction in an ideal smooth surface and therefore, lose in heat dissipation.

Temperature measuring test: In this test (Fig. 6) two thermocouples are used to measuring the temperatures at the base and tip surfaces of a fin of the heat sink by applying the following steps:

- Turning on the electrical heater (adjacent the base of the heat sink) and then control the power supplied to the heater by adjusting the voltage at a specified value using a regulator

- Heating the heat sink base to a specified temperature $\left(95^{\circ} \mathrm{C}\right)$

- Turn off the electrical heater and waiting until the reduction of temperature reaches steady a state

- The temperatures dropping from maximum value are measured at the tip of the heat sink for two cases under study with time (every $5 \mathrm{~min}$ )

- The final form curve of temperature versus time is shown in Fig. 7

\section{Numerical results}

Structural results: In the structural numerical analysis of the heat sink using ANSYS are done for both aluminum and aluminum-copper materials by applying interface pressure 177.7 and $155.2 \mathrm{KPa}$ for aluminum-cupper and aluminum materials, respectively which calculated using Eq. 5 and 6 and Table 1. The number of elements which used in meshing the heat sink model is 1034 has a trigonometric shape. The

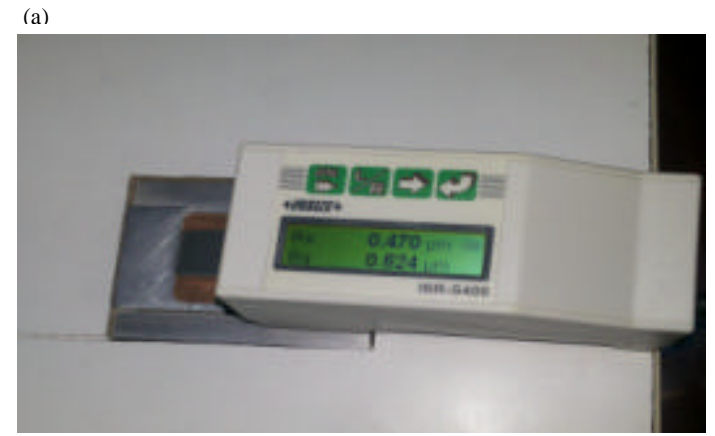

(b)

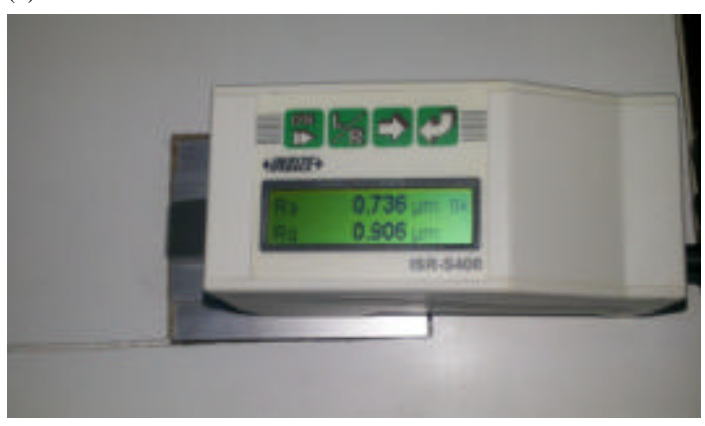

Fig. 4: Roughness test: a) Composite sink and b) Aluminum sink

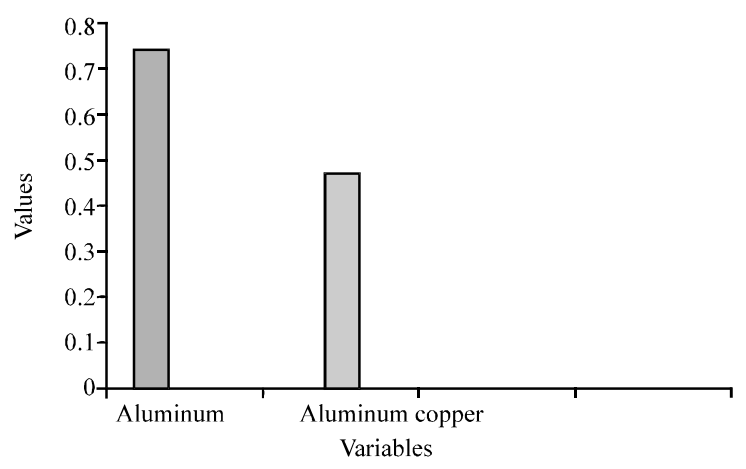

Fig. 5: Roughness measurement in $\mu \mathrm{M}$

maximum thermal deformations are too small only 6.058 and $6.777 \times 10^{-8} \mathrm{~m}$ for aluminum and composite sinks, respectively as shown in Fig. 8 in a deformed shape. The deformations are approaches to zero which identical to preview assumption in the current formulation of pressure equation.

The maximum Von-Misses stress in two models of heat sinks are 14.887 and $16.847 \mathrm{MN} / \mathrm{m}^{2}$ for old and new sinks, respectively as shown in Fig. 9. The factor of safety (which equal maximum stress to yield stress) is 2.35 of old sink while this value is increasing to 4.10 for a new sink with significant increment reached to $42.58 \%$, so, more safe design is determined. 


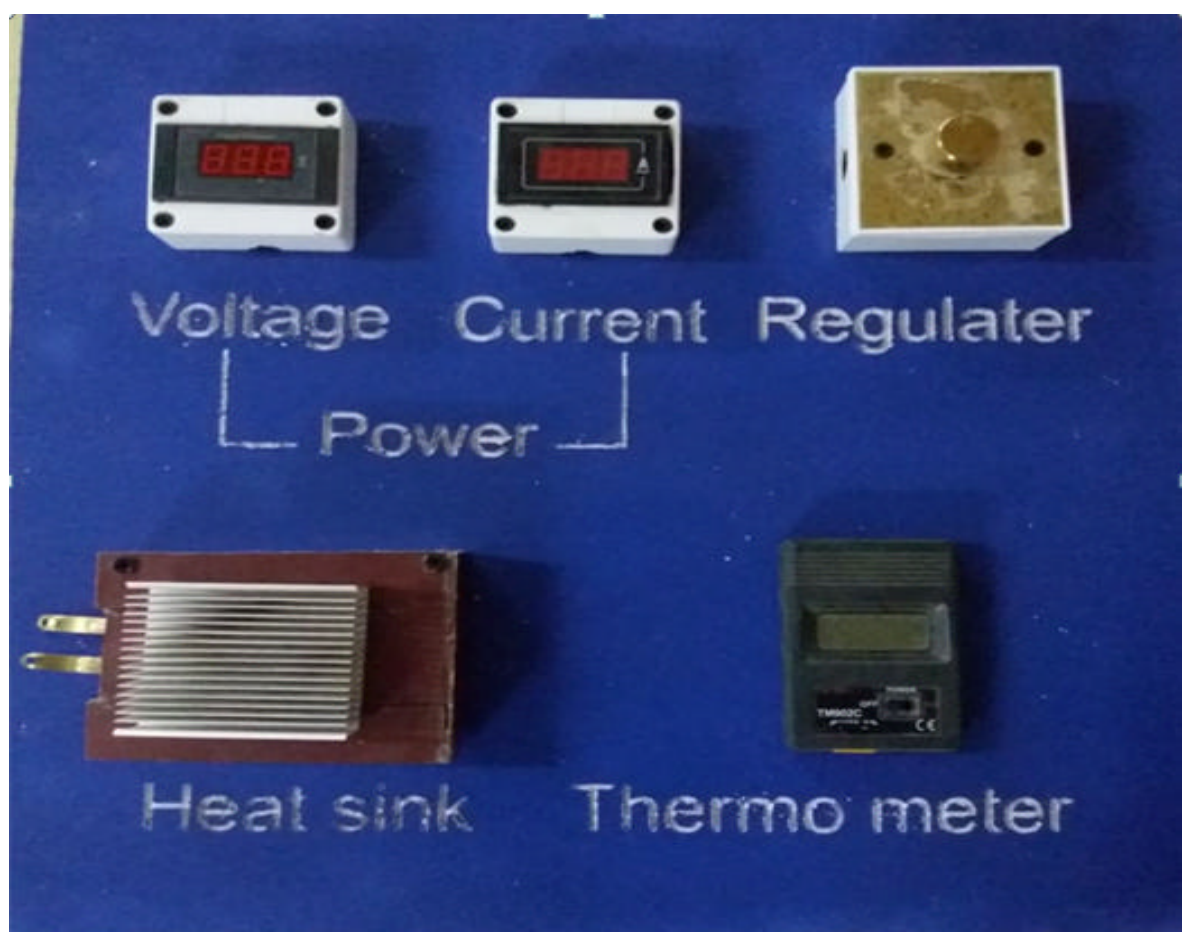

Fig. 6: Temperature measuring devices

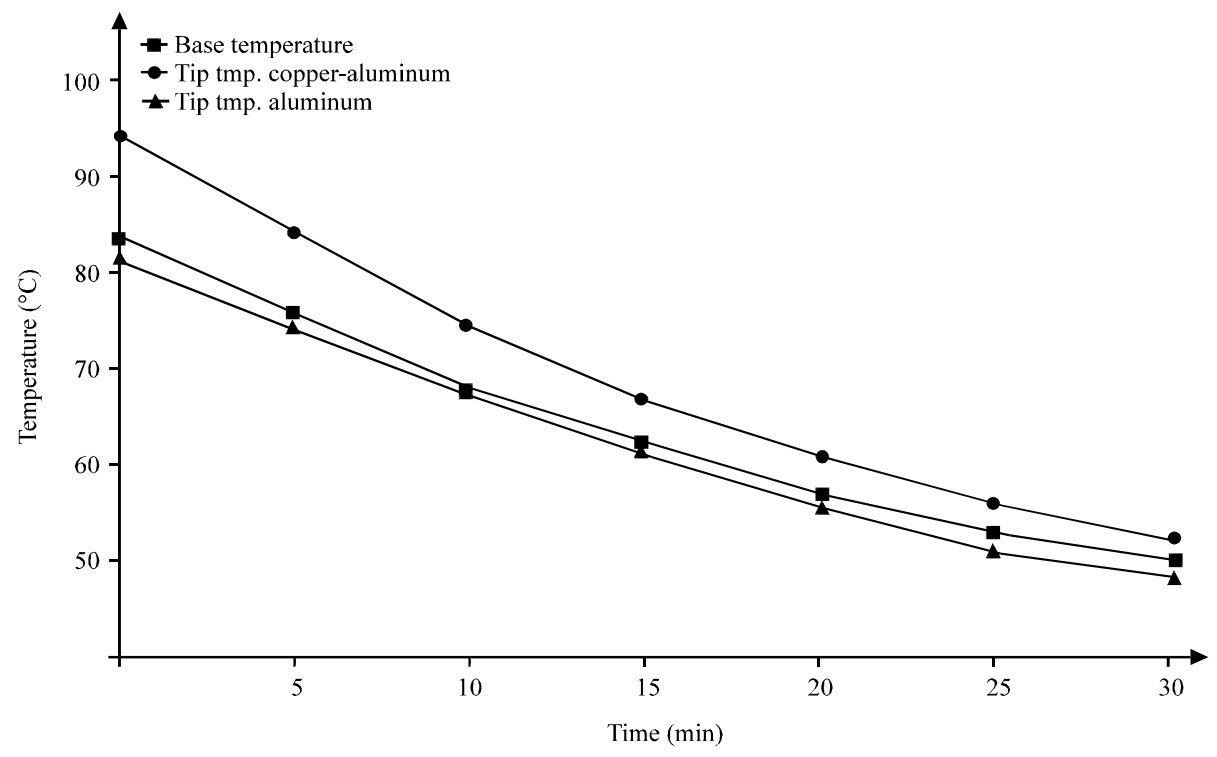

Fig. 7: Temperature gradient with time

Thermal results: The thermal investigation of current work is cover temperature distribution and heat flux dissipation in heat sink for two materials under study under conduction through the heat sink and convection from the fins to the air (calculated an empirical value of $\mathrm{h}=44.8 \mathrm{w} / \mathrm{m}^{2} \mathrm{k}$ ). Figure 10 is shown the distribution of temperature across the heat sink by putting $85^{\circ} \mathrm{C}$ in the base as boundary conditions (which already measured in experimental result) in ANSYS Program for two cases while slightly different in magnitude in the tips of fins 76 and $75^{\circ} \mathrm{C}$ for aluminum and copper-aluminum materials, respectively. The drawing of temperature gradient versus sink height is shown in Fig. 11 which clearly can be investigated that new composite material has better drop in temperature through the heat sink than an ordinary one. 
(a)

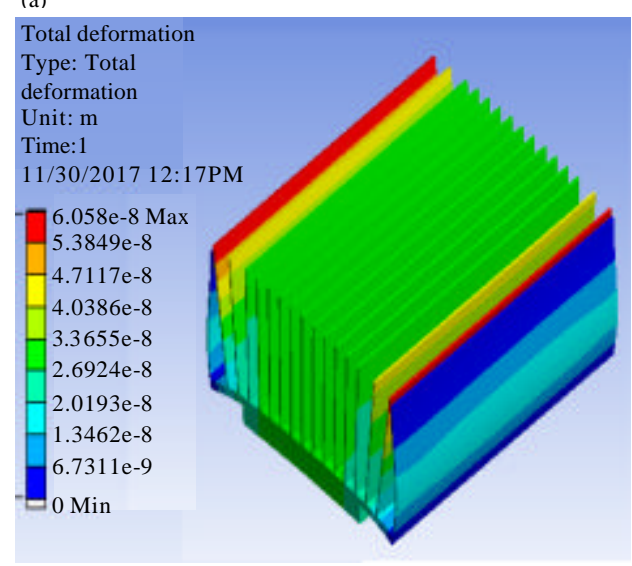

(b)

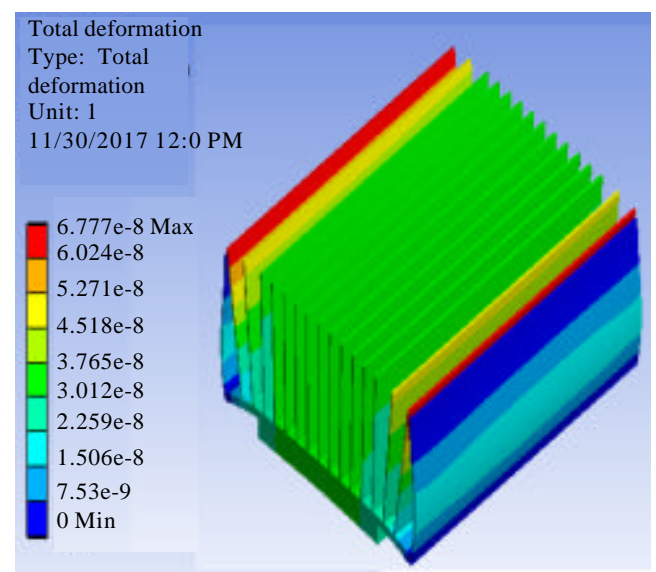

Fig. 8: Deformation of heat sink in m: a) Aluminum sink and b) Copper-aluminum sink

(a)

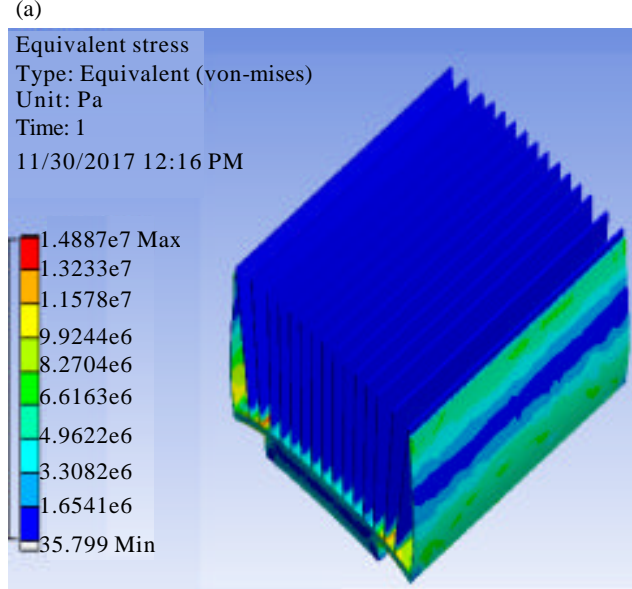

(b)

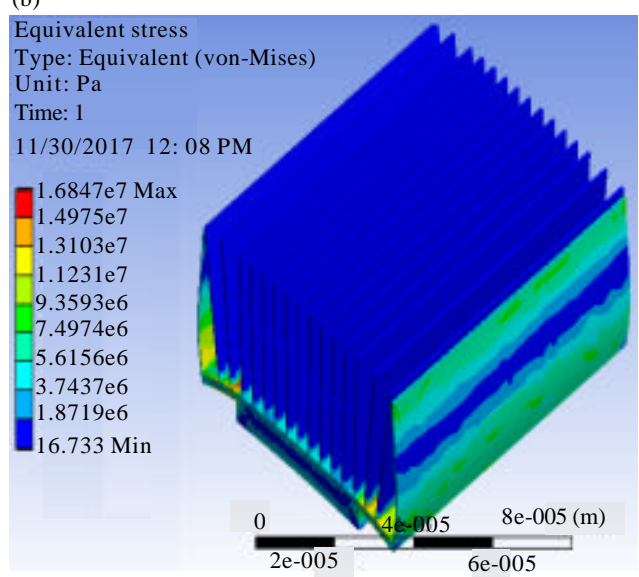

Fig. 9: Von-Misses stress of heat sink in $\mathrm{N} / \mathrm{m}^{2}$ : a) Aluminum sink and b) Copper-aluminum sink
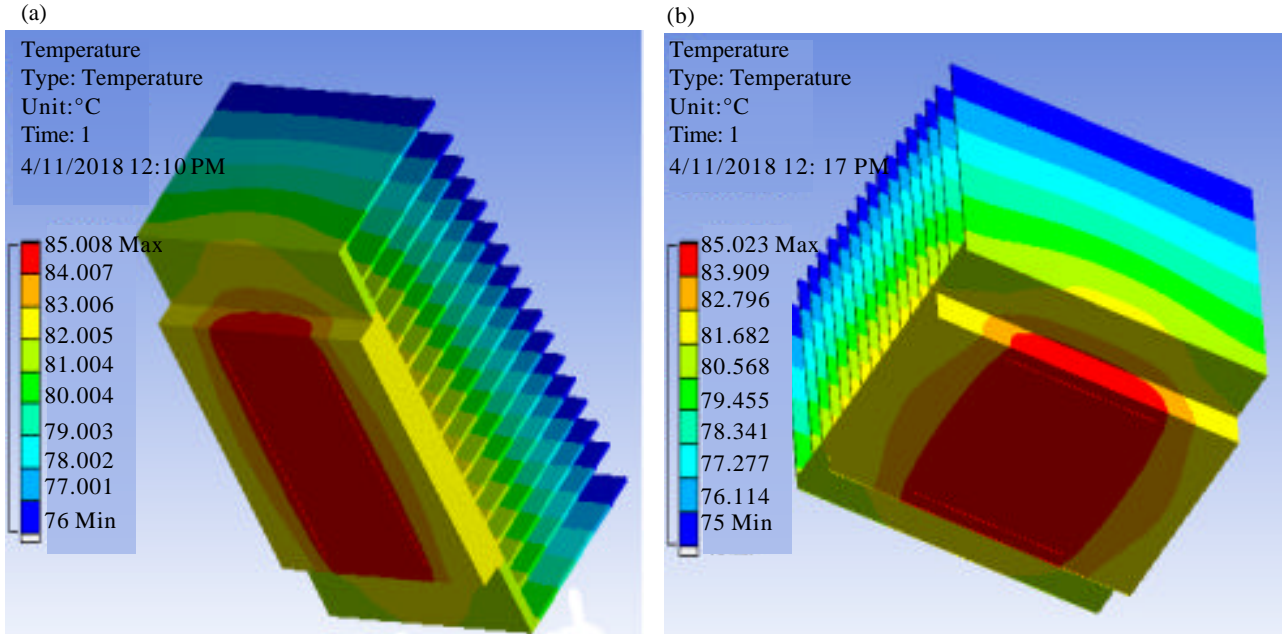

Fig. 10: Temperature distribution in heat $\operatorname{sink}$ in $\left({ }^{\circ} \mathrm{C}\right.$ : a) Aluminum sink and b) Copper-aluminum sink 


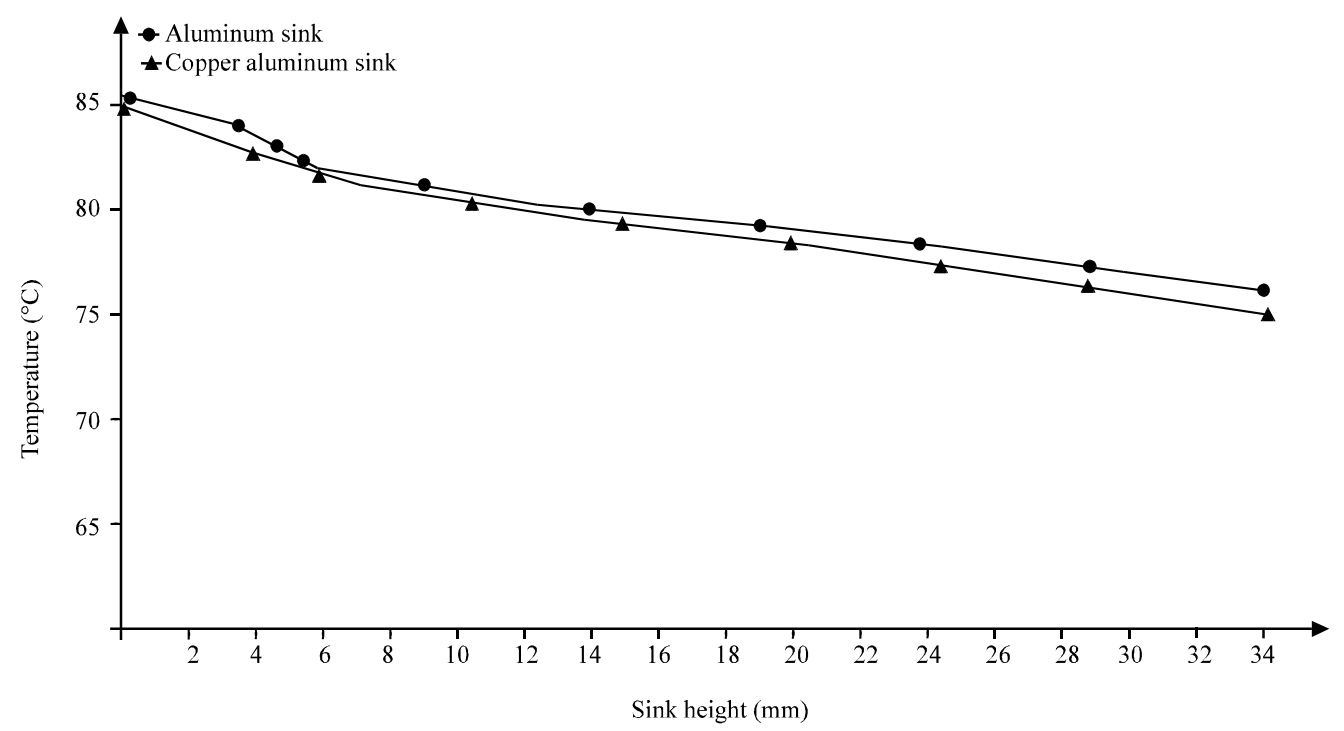

Fig. 11: Temperature drop across height of heat $\operatorname{sink}$ in $\left({ }^{\circ} \mathrm{C}\right)$ : a) Aluminum sink and b) Copper-aluminum sink

(a)

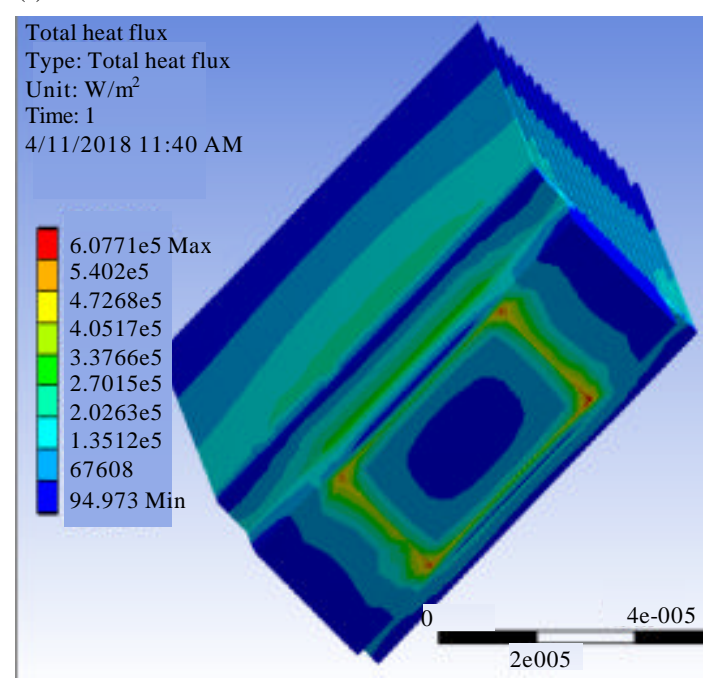

(b)

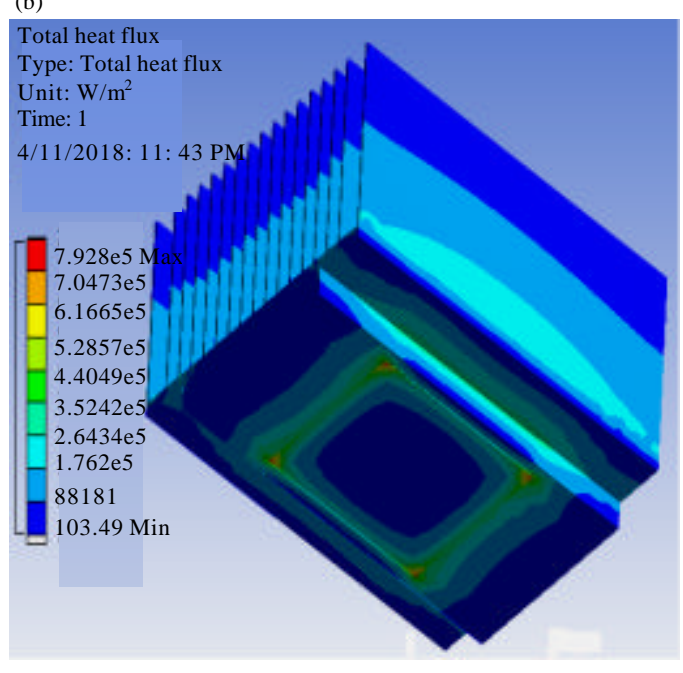

Fig. 12: Heat flux in heat sink in $\mathrm{W} / \mathrm{m}^{2}$ : a) Aluminum sink and b) Copper-aluminum sink

Table 2: Comparison of heat flux result (Chung, 2001)

\begin{tabular}{lcc}
\hline Cases & Base or junction temperature $\left({ }^{\circ} \mathrm{C}\right)$ & Ambient temperature $\left({ }^{\circ} \mathrm{C}\right)$ \\
\hline Present work copper-aluminum sink & 85 & 24 \\
Sink work with vapor chamber (Go, 2005) & 85 & 792.8 \\
\hline
\end{tabular}

The maximum heat dissipation from heat sinks are shown in Fig. 12, the new heat sink materials offer excellent heat reject of $792.8 \mathrm{kWlm}^{2}$ in comparison to only $607.7 \mathrm{kWlm}^{2}$ in the aluminum sink with high percentage decreasing to $23.3 \%$. The heat dissipation to weight ratio are 4.76 and $4.02 \mathrm{~kW} / \mathrm{m}^{2} \mathrm{~g}$ for new and old heat sink respectively is calculated by dividing present investigated values to against measured mass. The new copper aluminum sink is developed greater heat dissipation to weight ratio to about $15.5 \%$ than the old one. In order to make a comparison of the present work with other experimental investigations studies under same boundary conditions of heat rejected is shown in Table 2. The comparison is given good rapprochement in results with only $9 \%$ difference between present and (Go, 2005) results due to take different parameters like different heat sink size $(83.1 \times 69.1 \times 32.67 \mathrm{~cm})$ 
and materials (aluminum-stainless steel plate) in addition to other modes of heating of acetone-charged vapor chamfer (Go, 2005).

\section{CONCLUSION}

The main conclusions are investigated in the current research can be listed as follows:

- Adding a piece of copper at the base of a heat sink made from aluminum is improved heat rejection to $23.3 \%$

- Higher heat dissipation to weight ratio is obtained than an ordinary aluminum sink reached to $15.5 \%$

- Higher safety of sink design is determined by a significant increment in the factor of safety from 2.35-4.10

- The better surface of contact with the processor of $36.1 \%$ is obtained by copper piece surface in comparison with an ordinary aluminum surface

\section{NOMENCLATURE}

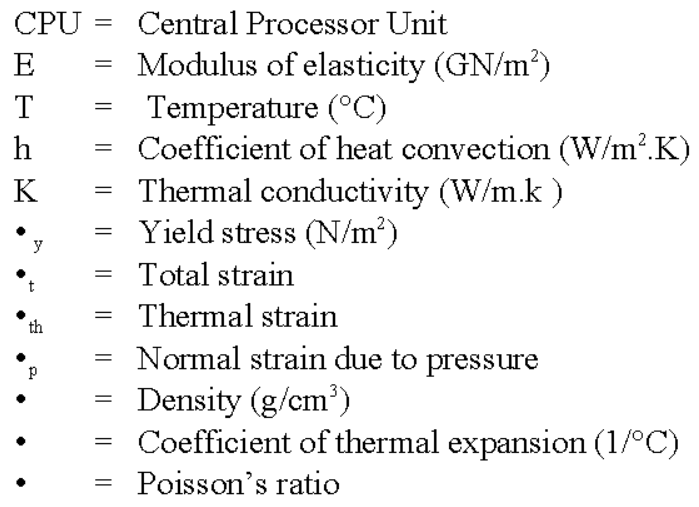

\section{REFERENCES}

Baviskar, P.V., K.A. Saner, N.P. Salunke and V.B. Jadhav, 2016. To analyze the effect of varying fin shapes for microprocessor cooling. Intl. J. Innovative Res. Sci. Eng. Technol., 5: 5613-5621.

Carr, J.D., 2014. An examination of CPU cooling technologies: Thermal management options for engineers. Master Thesis, DSI Ventures Inc, Tyler, Texas.
Chiang, J.S., S.H. Chuang, Y.K. Wu and H.J. Lee, 2005. Numerical simulation of heat transfer in a desktop computer with heat-generating components. Intl. Commun. Heat Mass Transfer, 32: 184-191.

Chung, D.D.L., 2001. Materials for thermal conduction. Appl. Therm. Eng., 21: 1593-1605.

Go, J.S., 2005. Quantitative thermal performance evaluation of a cost-effective vapor chamber heat sink containing a metal-etched microwick structure for advanced microprocessor cooling. Sens. Actuators A. Phys., 121: 549-556.

Kumar, V.M., S. Farooq and P.H.C. Prasad, 2016. CFD analysis on a heat sink by using grapheme. Intl. J. Sci. Technol. Manage., 5: 116-123.

Liu, Y.P., Z.P. Xu and Q. Zhu, 2012. The simulation and optimization of the CPU heat sink for a new type of graphite. J. Environ. Eng. Technol., 1: 8-11.

Magadum, P.P. and G.M. Shamrao, 2015. Analysis and optimization of processor cooling fins. Intl. J. Eng. Innovative Technol., 5: 90-94.

Mochizuki, M., Y. Saito, T. Nguyen, V. Wuttijumnong and $\mathrm{X}$. Wu et al., 2005. Revolution in fan heat sink cooling technology to extend and maximize air cooling for high performance processors in laptop/desktop/server application. Proceedings of the ASME 2005 Pacific Rim Technical Conference and Exhibition on Integration and Packaging of MEMS, NEMS and Electronic Systems, July 17-22, 2005, American Society of Mechanical Engineers, New York, USA., pp: 431-437.

Mohan, R. and P. Govindarajan, 2011. Experimental and CFD analysis of heat sinks with base plate for CPU cooling. J. Mech. Sci. Technol., 25: 2003-2012.

Navas, R.K.B., B.V.C. Vignan, M. Durganadh and C.R. Krishna, 2017. Analysis and optimization of central processing unit process parameters. Mater. Sci. Eng., 197: 1-10.

Saini, M. and R.L. Webb, 2003. Heat rejection limits of air cooled plane fin heat sinks for computer cooling. IEEE. Trans. Compon. Packag. Technol., 26: 71-79.

Tewari, I., N. Joshi, S. Sharma, P.S. Mehra and A. Melkani et al., 2017. Heat optimization of processor cooling by varying casing material. Intl. J. Emerging Technol., 8: 702-706. 